\title{
Modeling and simulation of photovoltaic systems and responsive loads in smart grid
}

\author{
Hamed MiRHABIBI ${ }^{1}$, Seyed Mehdi HAKIMI ${ }^{2} *$ \\ ${ }^{1}$ Department of Electrical Engineering, Islamic Azad University, Damavand Branch, \\ Damavand, Iran, Mirhabibi63@gmail.com \\ ${ }^{2}$ Department of Electrical Engineering, Islamic Azad University, Damavand Branch, \\ Damavand, Iran \\ *Corresponding author: $\underline{\text { sm_hakimi@damavandiau.ac.ir }}$
}

\begin{abstract}
In this paper, the methods of forecasting output at different times and applications within the smart grid photovoltaic system (PV) systems will be investigated method of calculations used in this short amount of solar radiation to consider the reduction in average for a few hours to compensate for power fluctuations and power reserve or battery operation and supply and demand balance is forecast. In this paper, the Monte Carlo simulation is used to predict the longterm average. Usually the use of the smart grid PV system problems and even load variation problems within the system are accountable in this study, and surpassed Weather amount of output power into a smart grid system used PV is the case in the field of innovation and new research in this paper uses three software HOMER, GAMS and MATLAB simulation of photovoltaic systems within a network smart look and accountability in the network will be supplied by the PV system will be examined.
\end{abstract}

Keywords: PV, smart grid, load-responsive

\section{Introduction}

In recent years, photovoltaic (PV) modules have become an increasingly more popular source of energy in both commercial and residential applications. This is partly a direct effect of the increased government incentives (tax credits and renewable energy credits, etc.) as well as a growing interest in diverting mankind's energy dependence on carbon fuels and other nonsustainable sources. It can be expected that the popularity of solar power and other sustainable sources of energy will continue to grow until the need for fossil fuels as a primary form of energy is significantly reduced. However, despite the many advantages of harnessing the sun's energy through the use of PVs, widespread deployment has been limited by economics in many locations of the world. This is due to a number of factors including, but not limited to; high upfront cost of installation, long payback period of the investment, inefficiencies of PV modules, 
and general lack of knowledge about the subject by the public. Currently, most photovoltaic arrays are installed by general contractors with little or no knowledge of the nature of PV cells/modules in operation and how they effectively generate power. These contractors often face a strict limit on the area available for a PV installation. As a result, modules are often arranged in a way that maximizes the density of modules per unit area rather than maximizing the efficiency of the modules' output. This area maximization will in many instances cause an increased incidence of shading of many modules in the array. This can be due to many sources; local obstructions on the building roof, adjacent buildings, natural obstructions such as trees, etc. [1]. The most common occurrence of shading from this maximization, however, on flat roof systems is caused by modules being shaded by the module rows in front of them. Although it is known that this shading causes significant efficiency loss, a direct transference of this knowledge to design guidance has been inadequately reported in the scientific literature. This paper attempts to elucidate how shading caused by subsequent rows of photovoltaic modules affects the efficiency of modules and the entire array as a result. While shading impacts are minimal when the sun is high in the sky, they become increasingly pronounced in the morning and evening, the latter period of keen interest to those investigating grid optimization and Smart Grid as these hours represent the peak demand period for many of the world's electrical systems. Numerous in-situ I$\mathrm{V}$ tests were run by our research team at the Center for Sustainable Design in which a PV module's power output was measured under varying levels of horizontal row shading across the lower cells of the module. Module power production was measured by systematically varying resistance of the load on the module and recording the product of the voltage and current. Sensors detecting and reporting insolation normal to the module and module temperature were also employed for each run to help take into account other sources that may be responsible for the changing power output. By expanding our understanding of the relationship between partial shading and module efficiency, optimization of the balance between maximum module density per area and minimum module shading can be achieved to maximize power output during peak demand which will eventually become a significant value driver in Smart Grid applications of PV. This knowledge can lead to the development of key Smart Grid guidelines for this important renewable power source that will assure these typically intermittent resources have a greater potential for availability during summer peaking utility's peak demand periods. This data can be used to optimize all the important design parameters with respect to inter row shading for gridconnected, roof and ground mounted PV systems. Practical and feasible systems have tool for become electric globally power accepted generation. As a Researchers' efforts for facilitating PV systems utilization and their integration to currently available systems have been always inspired by the national goal of having renewable and clean energy sources. These efforts successfully solved many of the problems that are attached to PV systems [1]. Generally, PV systems are of two types; grid-connected and stand-alone PV systems. Although grid-connected PV systems are designed to operate in parallel with the utility network, grid-connected PV systems may feed local loads independently from the utility grid in an islanded mode during outages. Moreover, they may involve battery storage or other generating sources in order to increase the overall 
reliability of the system. On the other hand, stand-alone PV systems are designed to supply power to certain loads independently from the utility Moreover, these PV systems can supply AC loads but in this case an added DC-AC inversion has to be involved. Generally, there are three types of stand-alone PV systems, PV-powered water pumping systems, Remote residential PV systems and PV-powered lighting systems. One of the major problems of PV systems is that the output voltage of PV panels is highly dependent on solar irradiance and ambient temperature. Moreover, the voltage/power characteristics of PV arrays are nonlinear [2]. An algorithm has to be implemented to track the maximum power point (MPP). Different algorithms have been proposed in literature for maximum power point tracking [3],[4]. Hence, loads cannot be directly connected to the output of PV panels. Different power electronic converters have to be used as interfaces between the PV array and the loads. These converters are usually called power conditioning units (PCU).

\section{Smart grid structure}

Microgrid used in this project is shown schematically in Figure 1. The micro-grid connected upstream is in original condition and Fashion Island is also able to provide the required 80 percent of the time. The micro-grid to model the demand response program (DR) of variable load is applied. The microgrid components include the following. in Figure 1 shown the microgrid structure.

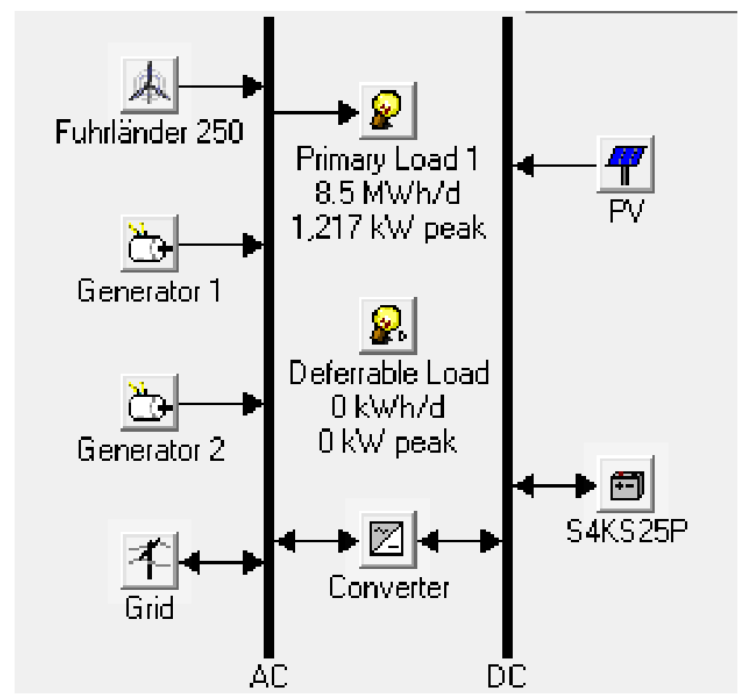

Fig 1: Smart grid structure

\section{The main design criterion value}

This criterion is, in fact, mean uncertainty of each project. This criterion is the most important criterion is weighted more to this standard makes the plan less than the initial cost of pollution or other designs better than other projects selected. It took more risks, and on the other hand is a better design choice. After weighing the various designs of the different criteria to 
arrive at the optimal design of the layout is better. The idea is number 3 . The proposals 1 and 2 of this project are better, but because of the use of all technology initiatives (3) is selected. Plans relative to each other are worth as Figure 2.

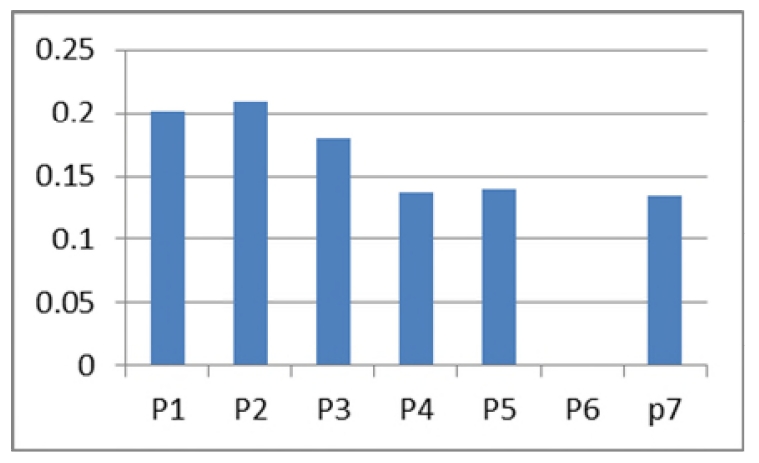

Fig 2: Bar graph value projects to each other

This article includes a photovoltaic system, eight wind turbines, diesel generators power output is 1000 and the converter. In this system, the ability to buy and sell electricity from the grid is available, but the quantity is limited. Sure, you can view a different look to it that to do so at a higher level, has developed a decision tree.

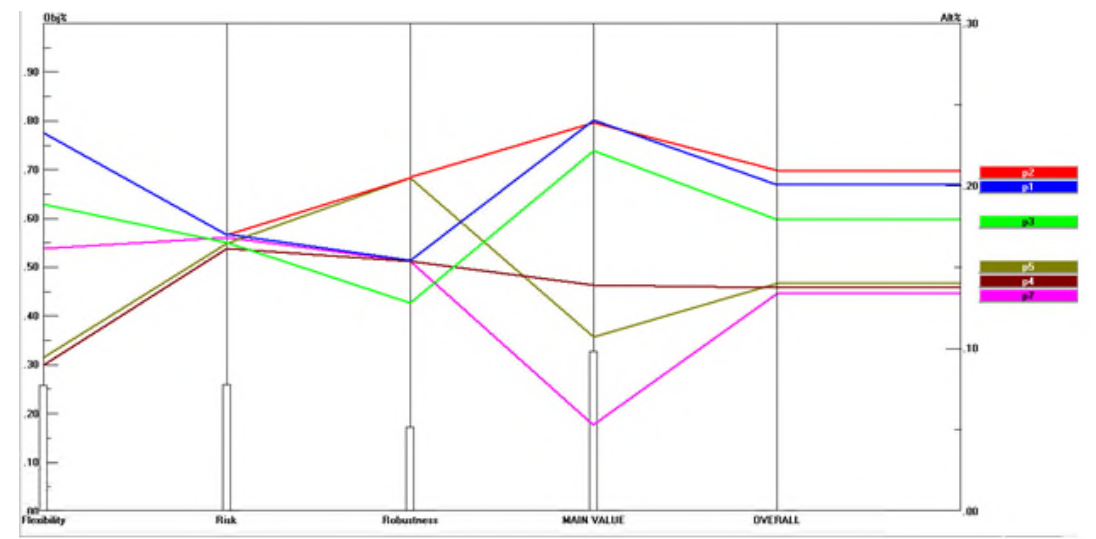

Fig 3: Study different designs based on three criteria to evaluate the indicators

\section{The operation of the microgrid within 24 hours}

The operation of the network has been designed using GAMS code. The program has a few things to be considered. A non-linear operation for optimal target (nlp) is considered. This program is not implemented in the unit commitment and the reason for this is that the programs that are considered to be the unit commitment, to factors such as minimum when the units, minimum stay off units, the cost of power units, The increase or decrease in production capacity and ... be considered. In this design, these factors are not considered. However, adding these constraints and binary variables can be solved minlp Imagine program. 
Wind turbine and photovoltaic units are considered as renewable sources. Due to low production of these units, these resources as a source of control outputs have been considered. It can be used to define the minimum and maximum production sources, such as generators operation. This photovoltaic system will fail. LIMITATION sales network has been around 20\% load Intended load on the first day of summer is considered. The prices of electricity purchased from the grid and sold to the network are placed in 3 groups. Note that unlike plan is in the HOMER software. Because the purchase price and the sale of electricity and the price of electricity sold to the grid defined separately rather than buying it. To solve the program, the program has been used nlp using solver IPOPE. Note that by reducing the restrictions on the purchase and sale of the network and the network to increase the range of the purchase of additional time provided by the network. The resulting output of operation 24 hours a day on the pictures below are available. Figure 4 shows a bar graph of time.

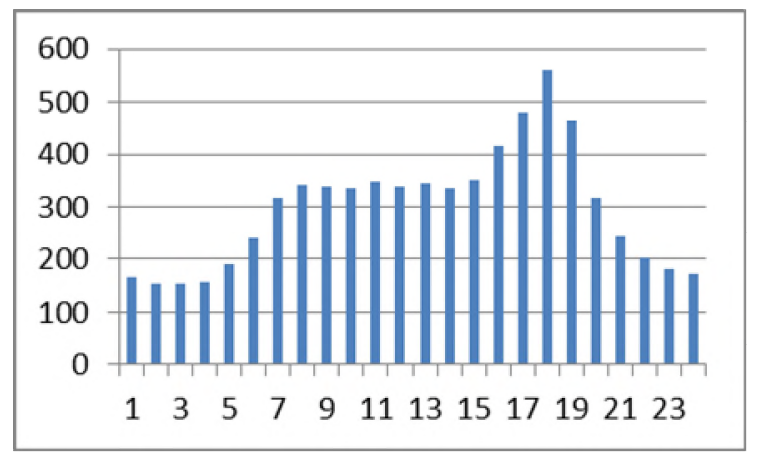

Fig 4: Bar graph load

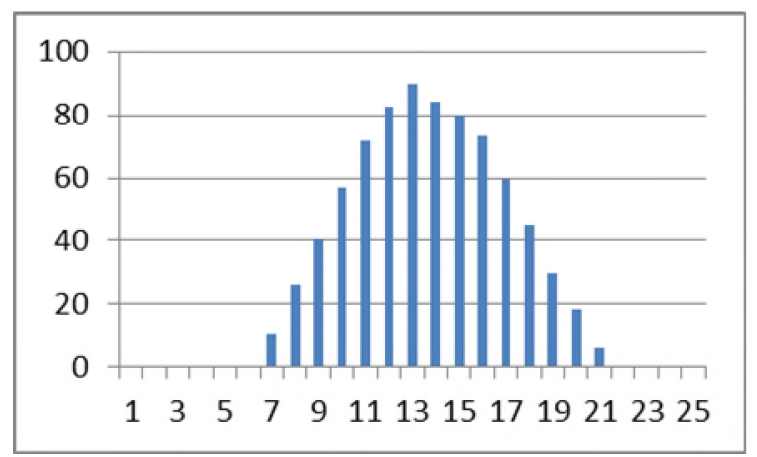

Fig 5: Bar graph of output power PV 
Bulletin de la Société Royale des Sciences de Liège, Vol. 86, special edition, 2017, p. 550 - 558

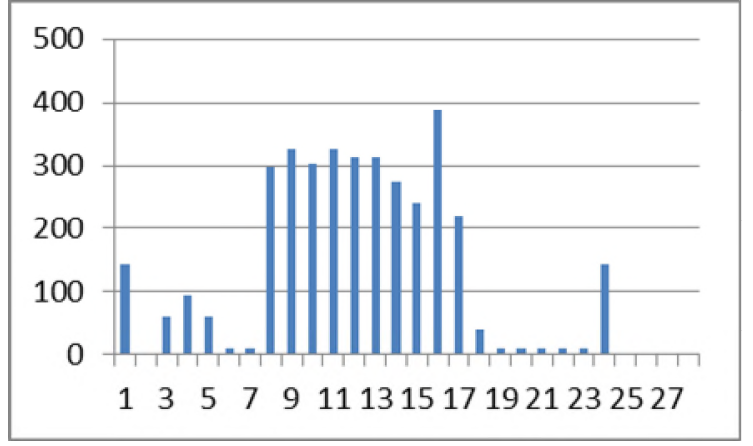

Fig 6: Output power of the wind turbine

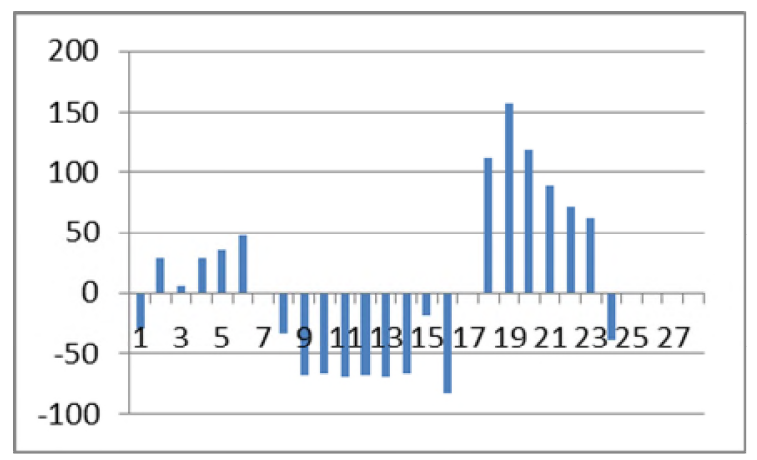

Fig 7: Output power of grid

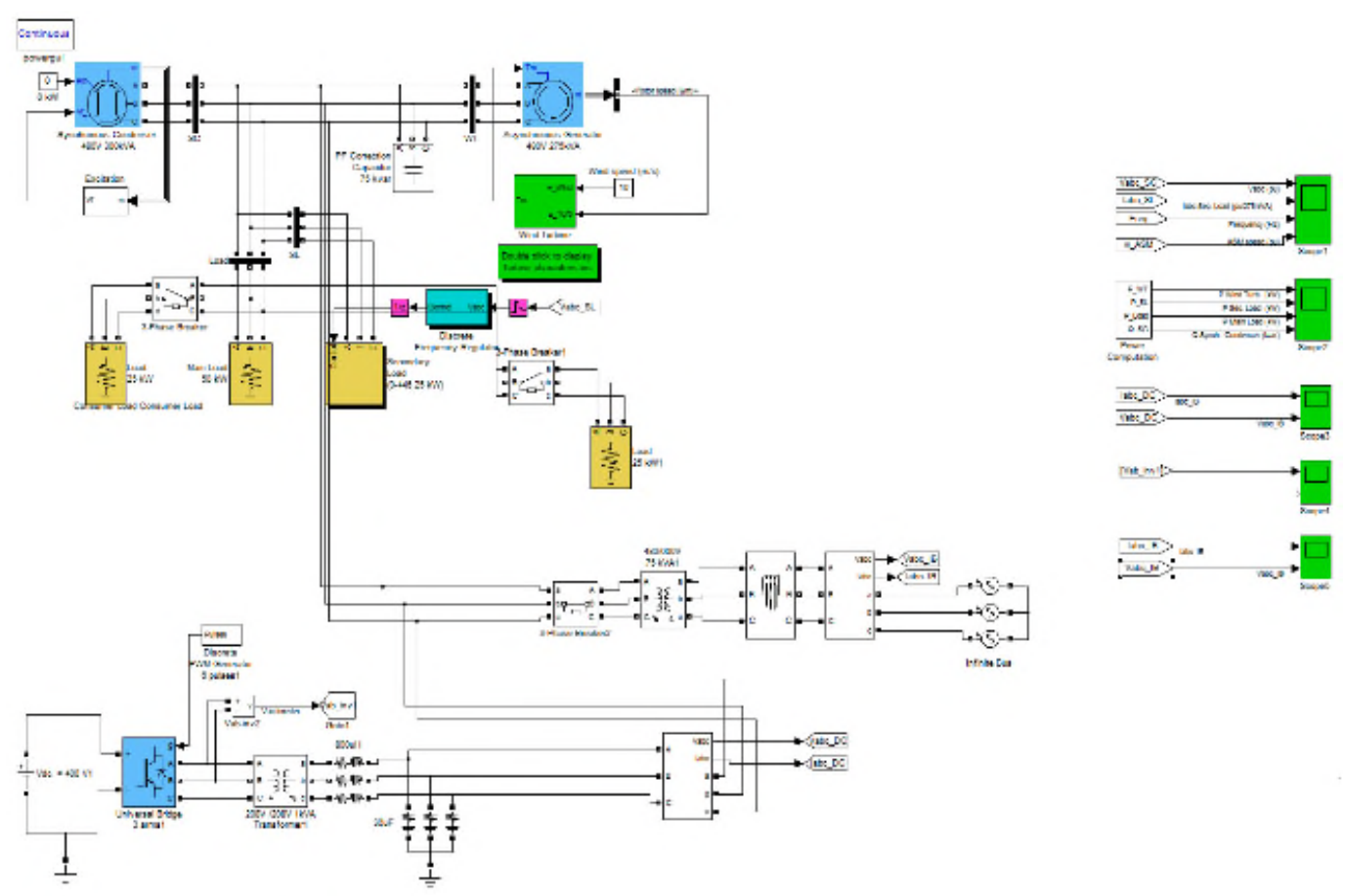

Fig 7: Designed Micro-grid 


\section{Result}

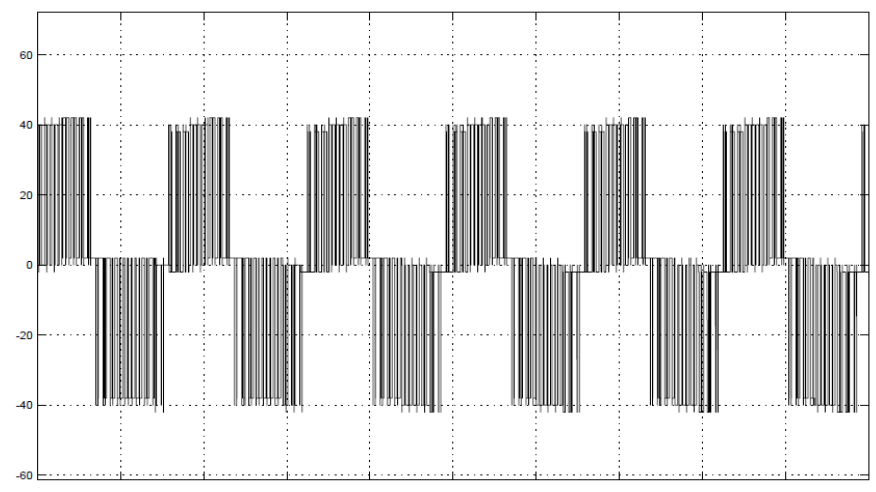

Fig 8: Inverter output voltage of the solar cell

Note that when the frequency is above $60 \mathrm{~Hz}$, the second load began to grow, and with it goes $60 \mathrm{~Hz}$ frequency level. Due to transient conditions and to limit the input power from the grid frequency is $60 \mathrm{~Hz}$ in the first seconds can not be fixed.figure 9 shows this matter.

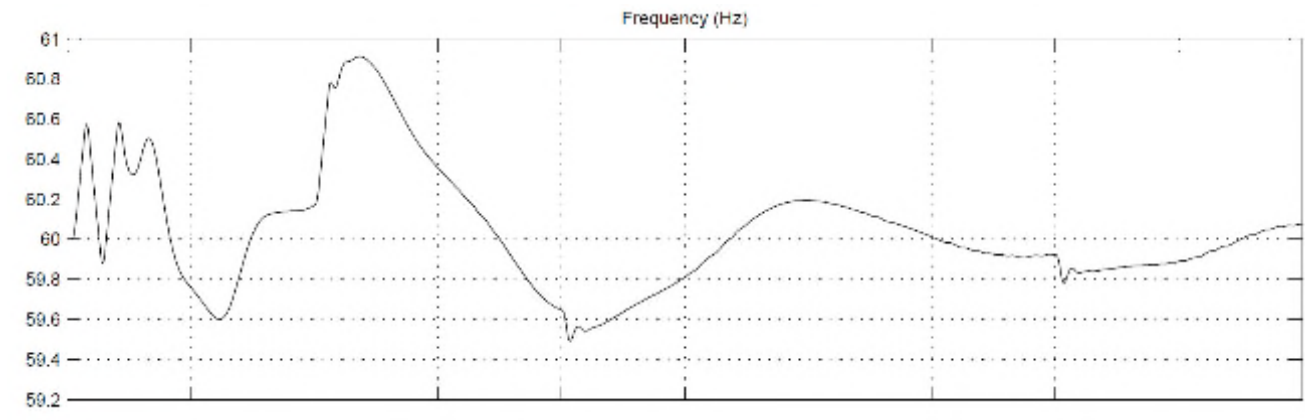

Fig 9: Network frequency $5 \mathrm{~s}$

Frequency graph shows the frequency not to remain constant over time. In any case, note that the fluctuation is $\pm 1 \mathrm{~Hz}$. These changes microgrid for low inertia and larger networks, these changes are less. Another important point is that at that load to the network, the frequency falls and it at times $2 \mathrm{~s}$ and $4 \mathrm{~s}$ happened. Figure 10 shows this matter. 


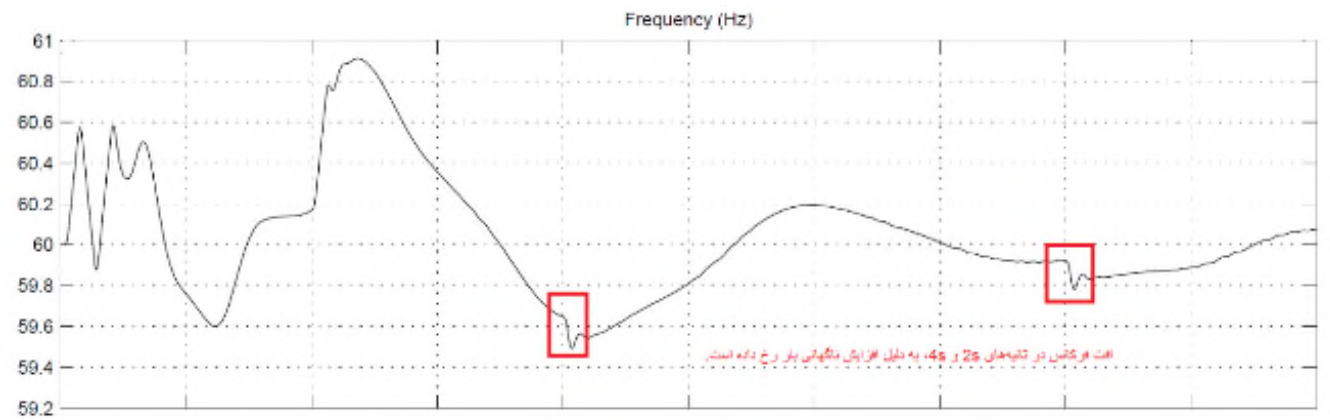

Fig 10: Frequency loss due to sudden load changes

Figure 11 related to speed synchronous generator, and the turbine is located. In fact, maximum power output of the wind turbine is determined by the wind, but that is how much electrical power output of wind turbines can be determined. This is done by setting speed asynchronous generator. Note that the main producer and supplier in the micro-grid wind turbine is done by the manufacturer.

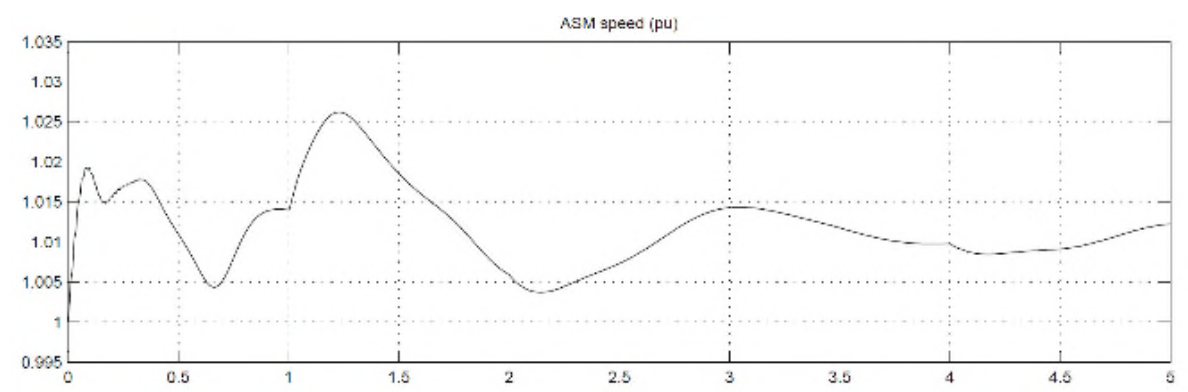

Fig 11: Speed synchronous generator ranged 5s

\section{Conclusion}

In this paper, the fluctuation is $\pm 1 \mathrm{~Hz}$. These changes microgrid for low inertia and a larger network this change is less and microgrid goes to the island. Increased frequency means that DGs, the network is considered as a burden and inject energy to the grid. With a network outage, the microgrid taken time and frequency increase, followed by the electric generator speed increases. The Times also consists of two parts: the main bar and the second time Second time is the time that is sensitive to changes in the network. This time, in fact, balanced network. Where production is greater than consumption, the load and to increase the voltage level setting. Second and fourth times per second, a sudden increase in the load circuit through breakers and connect it with the $2 \mathrm{~s}$ and $4 \mathrm{~s}$ breakers at a time is possible. 
Bulletin de la Société Royale des Sciences de Liège, Vol. 86, special edition, 2017, p. 550 - 558

\section{References}

[1] T. Khatib, A. Mohamed and N. Amin, "A new controller scheme for photovoltaics power generation systems," European Journal of Scientific Research, vol. 33, no. 3 (2009) 515-524.

[2] Marcelo Gradella Villalva, Jonas Rafael Gazoli, and Emesto Ruppert Filho, "Comprehensive Approach to Modeling and Simulation of Photovoltaic Arrays," IEEE Trans. On Power Elec., vol. 24, no. 5 (2009) 1198-1208.

[3] Trishan Esram and Patrick L. Chapman, "Comparison of Photovoltaic Array Maximum Power Point Tracking Techniques," IEEE Trans. On Energy Conv., vol. 22, no. 2 (2007) 439449.

[4] Cuauhtemoc Rodriguez, and Gehan A. J. Amaratunga, "Analytic Solution to the Photovoltaic Maximum Power Point Problem," IEEE Trans. on Circuits and Systems-I: Regular Papers, vol. 54, no. 9 (2007) 2054-2060.

[5] V. Salehi, A. Mohamed, A. Mazloomzadeh, O. Mohammed, "Laboratory-Based Smart Power System, Part I: Design and System Development," accepted in IEEE Transaction on Smart Grid. In press.

[6] V. Salehi, A. Mohamed, A. Mazloomzadeh, O. Mohammed, "Laboratory-Based Smart Power System, Part II: Control, Monitoring and Protection," accepted in IEEE Transaction on Smart Grid. In press.

[7] M. Elshaer, A. Mohamed and O. Mohammed "Grid Connected DC Distribution System for Efficient Integration of Sustainable Energy Sources," in Proc. of IEEE Power Systems Exposition, PSCE 2011, Phoenix, Arizona, USA 20 -23 May 2011.

[8] A. Mohamed, Mohamed. Elshaer and Osama Mohammed, "BiDirectional AC-DCIDC-AC converter for Power Sharing of Hybrid ACIDC Systems," in Proc. of IEEE PES General Meeting 2011, Detroit, Michigan, USA

[9] M. Elshaer, A. Mohamed and O. Mohammed, "Integration of Sustainable Energy Sources into DC Zonal Electric Distribution Systems," in Proc. of IEEE PES General Meeting 2011, Detroit, Michigan, USA.

[10] A. Mohamed, M. Elshaer, O. Mohammed, "High-Quality Integration of Fuel Cells Energy into Electric Grids," in Proc. Of 4th International Symposium on Resilient Control Systems, ISRCS 2011, Boise, Idaho, USA, Aug. 9-11, 2011.

[11] Ahmed Mohamed and Osama Mohammed, "Smart Optimal Control of DC-DC Boost Converter in PV Systems," in Proc. of the Transmission and Distribution Conference and Exposition: Latin America (T\&D-LA), 2010 IEEEIPES, pp. 403-410, Sao Paulo, Brasil, Nov. 2010.

[12] D. Nilsson and A. Sannino, "Efficiency analysis of low- and mediumvoltage de distribution systems," IEEE PES General Meeting, 2004.

[13] A. Mohamed, M. Elshaer, O. Mohammed, "Control Enhancement of Power Conditioning Units in Photovoltaic Systems," accepted in Electric Power System Research, Elsevir, In press. 